\title{
COMPOSIÇÃO FLORÍSTICA DE UM FRAGMENTO FLORESTAL CILIAR NO SUL DE SANTA CATARINA
}

\section{FLORISTIC SURVEY OF A RIPARIAN FOREST REMNANT SOUTHERN SANTA CATARINA STATE, BRAZIL}

\author{
Vanilde Citadini-Zanette; Robson dos Santos ${ }^{1}$ \\ Kleber Haileê Emerich; Marcelo Romagna Pasetto ${ }^{2}$ \\ Jean Gabriel Cemin; Marciel Bonfim Fernandes ${ }^{3}$
}

\begin{abstract}
Resumo
Apresenta-se resultado de levantamento florístico em área de mata ciliar pertencente à Floresta Ombrófila Densa Submontana, em área urbana, no município de Turvo, sul do estado de Santa Catarina. Registraram-se mensalmente, pelo método de caminhamento, as espécies de diferentes hábitos de crescimento que se apresentavam férteis na floresta. Adicionalmente, aspectos sucessionais e da biologia reprodutiva (polinização e dispersão) das espécies registradas foram também levantados a partir de pesquisa bibliográfica. Foram identificadas 100 espécies pertencentes a 49 famílias, sendo 49 espécies arbóreas, 19 arbustivas e as demais herbáceas terrícolas, lianescentes e epifíticas, encontradas na borda e interior da mata e beira do rio. Destas, 95 são angiospermas e cinco monilófitas. As famílias mais representativas foram as Myrtaceae, Rubiaceae, Euphorbiaceae, Melastomataceae, Fabaceae, Moraceae, Poaceae e Piperaceae. As demais apresentaram de uma a três espécies. A inclusão de diferentes hábitos, no presente estudo, permitiu uma ampliação no conhecimento florístico das formações ciliares remanescentes, embora com perturbações verificadas no passado.

Palavras-chave: Diversidade, Mata Atlântica, floresta ripária.
\end{abstract}

\begin{abstract}
The results from a floristic survey carried out in a riparian forest remnant of Submontane Dense Ombrophilous Forest, in urban area, in Turvo municipality, South of Santa Catarina state are presented The species occurrence was monthly registered, by the walking method, including all different life forms found fertile in the forest. Additionally, successional and reproductive biology aspects (pollination and dispersion) of the species were also registered from a literature survey. It was identified 100 species belonging to 49 families, being 49 trees species, 19 shrubs and the other ones terricolous herbaceous, lianas and epiphytes species, found inside and around the forest and at the edge of the river. Among these 100 species, 95 were angiosperms and 5 are monilophytes. The most representative families were Myrtaceae, Rubiaceae, Euphorbiaceae, Melaslomataceae, Fabaceae, Moraceae, Poaceae and Piperaceae. The other ones presented from one to three species. The different habits inclusion, in the present study, allowed a floristic knowledge broaden of the remaining riparian formations, although having disturbance verified in the past.

Keywords: Diversity, Atlantic forest, riparian forest.

\footnotetext{
${ }^{1}$ Docente do Programa de Pós-Graduação em Ciências Ambientais (PPGCA), Herbário Pe. Dr. Raulino Reitz (CRI), Universidade do Extremo Sul Catarinense (UNESC), Criciúma, Santa Catarina.

${ }^{2}$ Mestre em Ciências Ambientais, PPGCA, UNESC.

${ }^{3}$ Bolsista do Programa de Iniciação Científica (PIBIC e PIC-170), UNESC.
} 


\section{INTRODUÇÃO}

A Floresta Ombrófila Densa, em Santa Catarina, está situada em todo litoral, entre o planalto da Serra Geral e o oceano Atlântico a uma altitude de 5 a 1000 m (IBGE, 1992). Esta formação é a mais heterogênea e complexa do sul do país e seus ambientes mais expressivos encontram-se de 30 à $1000 \mathrm{~m}$ de altitude, apresentando nesses locais limites máximos de complexidade e de biodiversidade (LEITE; KLEIN, 1990). Ao longo das margens de seus cursos de água, das nascentes até a foz, engloba formações florestais denominadas de florestas ou matas ciliares (GHODDOSI; FRANK, 2007).

As matas ciliares cumprem importantes funções na manutenção do regime hídrico da bacia hidrográfica, na alimentação e abrigo da fauna, na estabilidade dos ambientes, contribuem para a recarga dos aqüíferos subterrâneos e servem de barreira física para a entrada de sedimentos nos cursos de água (LIMA; ZAKIA, 2001; ALVARENGA, 2004). Além disso, desempenham papel importante na formação dos corredores de fluxo gênico, podendo interligar populações vegetais que foram separadas pelo processo de fragmentação (KAGEYAMA; GANDARA, 2001). Estas matas contribuem ainda para o tamponamento e filtragem de nutrientes e/ou agrotóxicos, para a interceptação e absorção da radiação solar (MARINHO FILHO; REIS, 1989; PETTS 1990; SABINO; CASTRO 1990).

Apesar de serem protegidas por legislação federal e estadual, estas formações vegetais vêm sendo continuamente destruídas em várias localidades brasileiras (SALIS et al., 1994; FAGUNDES; GASTAL JUNIOR, 2008; GRACIOLI; ROCHA, 2008) assim como em Santa Catarina (FRANK, 2007). No sul de Santa Catarina, a fragmentação florestal, que também atinge as matas ciliares, na maior parte das vezes ocorre devido à substituição de parte da floresta por pastagens e atividades agrícolas. Além disso, as pressões humanas sobre estas fisionomias têm ocasionado a formação de pequenos fragmentos esparsos, em sua grande maioria perturbados (CITADINIZANETTE, 1995; REBELO, 2006).

Há necessidade de se avaliar a diversidade biológica contida nos atuais fragmentos, bem como compreender a organização estrutural da comunidade arbórea, face às variações ambientais, e a direção das mudanças nos processos ecológicos. Estas informações podem fornecer importantes subsídios que possibilitarão avaliar os 
potenciais de perdas e conservação dos recursos naturais em longo prazo (BOTREL et al., 2002).

Nesta perspectiva, apresenta-se resultado de pesquisa que objetivou reunir informações sobre a composição florística e as estratégias de polinização e dispersão e hábitos de vida das espécies vegetais vasculares encontradas em um fragmento mais conservado de floresta ciliar do rio Turvo, presentemente alterado em suas características ao longo de sua extensão.

\section{METODOLOGIA}

O estudo foi realizado em fragmento de floresta ciliar localizado às margens do rio Turvo, sul de Santa Catarina (Município de Turvo, 28 54' - 2855' S e 4941' $\left.49^{\circ} 41^{\prime} \mathrm{W}\right)$.

O rio Turvo nasce na base dos contrafortes da escarpa da Serra Geral, nos limites entre o município de Timbé do Sul com Turvo, percorrendo cerca de 8.800 metros em amplos terrenos planos dos leques aluviais até desembocar no rio Itoupava, do qual é um dos tributários afluentes. Apresenta padrão de canal meândrico de alta sinuosidade e restrita sedimentação aluvial (ALEXANDRE, 2000). Faz parte da bacia hidrográfica do Araranguá, a terceira maior do Estado.

A área estudada, situada próxima à sede do município de Turvo (Figura 1), encontra-se em zonas de transição entre as escarpas da Serra Geral e as planícies costeiras do litoral sul catarinense, na altitude de 32 metros s.n.m, o que a caracteriza como Floresta Ombrófila Densa Submontana (IBGE, 1992).

$\mathrm{Na}$ área estudada houve plantio de eucaliptos em épocas passadas. Segundo proprietário do terreno, os eucaliptos foram extraídos de forma seletiva de dentro da floresta secundária que se formou, deixando a área em processo de recuperação a mais de 50 anos. Ainda se encontram vários representantes dessa espécie, entremeados com a vegetação nativa.

A região onde se insere o remanescente estudado está classificada como do tipo Cfa, ou seja, mesotérmico, úmido, sem estação seca definida e com verões quentes (OMETTO, 1981). Dados coletados na Estação Experimental de Urussanga (28³1'55" $\mathrm{S}, 49^{\circ} 18^{\prime} 53^{\prime \prime} \mathrm{W}$ e $48 \mathrm{~m}$ de altitude), distante $58 \mathrm{~km}$ da área de estudo, registraram para o período de 30 anos, compreendido entre 1978 a 2008, temperaturas que variam de 
$42,2^{\circ} \mathrm{C}$ (máxima) e $4,6^{\circ} \mathrm{C}$ (mínima), com média anual de $19,2^{\circ} \mathrm{C}$. O inverno é frio e úmido com geadas ocasionais. As chuvas são bem distribuídas durante as estações do ano, não ocasionando longos períodos de secas e nem inundações frequentes.

O solo na área de estudo é classificado como Cambissolo Distrófico (EMBRAPA, 2005).

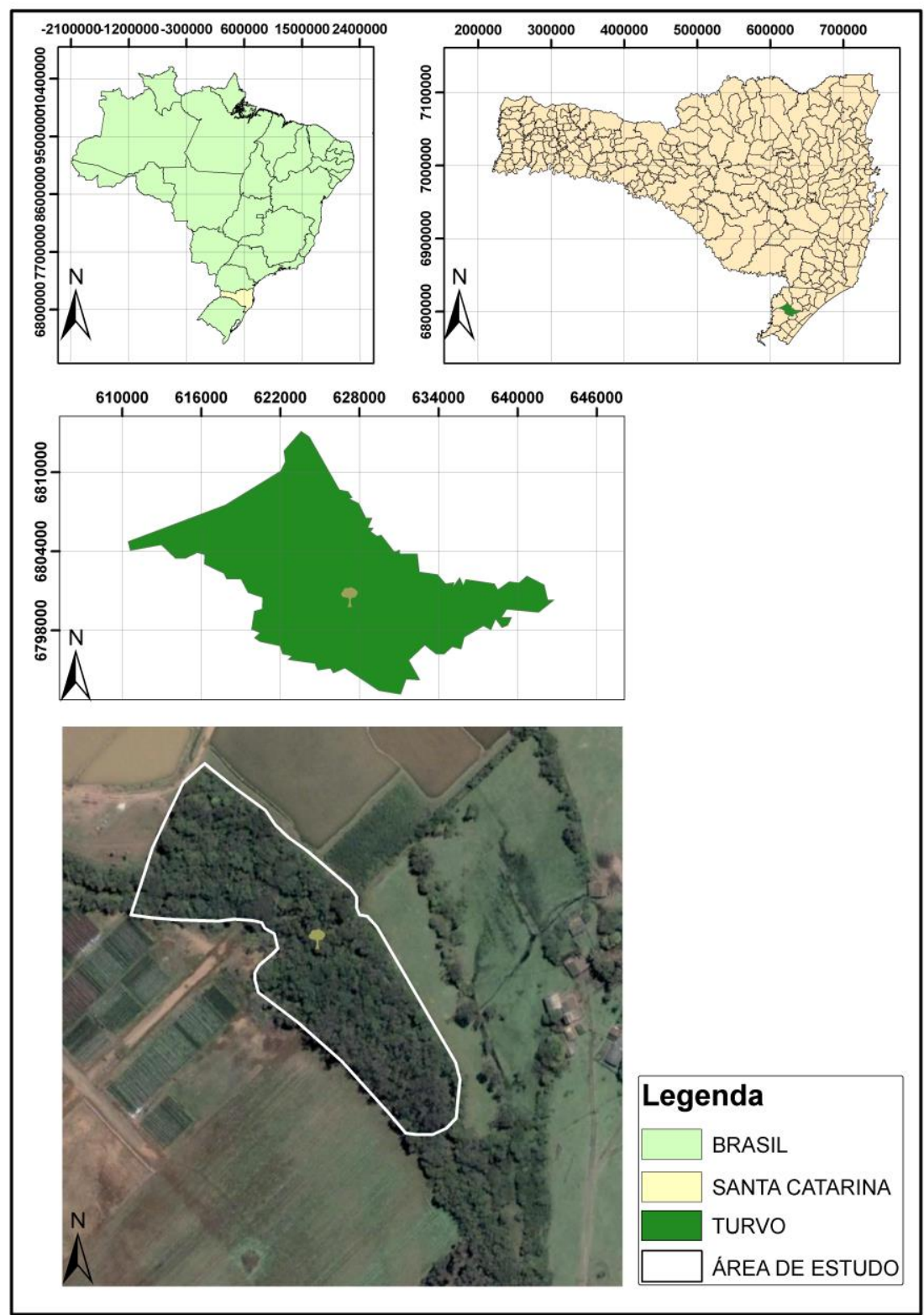

Figura 1. Localização geográfica do estado de Santa Catarina, com destaque ao município de Turvo, em detalhe, a área de estudo no fragmento de Floresta Ombrófila Densa Submontana, no rio Turvo, município de Turvo, Santa Catarina. 
Para o levantamento florístico empregou-se o Método de Caminhamento Expedito (FILGUEIRAS et al., 1994). Foram registradas todas as espécies vasculares de diferentes formas de vida, quando encontradas férteis. As coletas foram realizadas mensalmente entre agosto de 2007 a julho de 2008. Foram levantadas as espécies presentes nas duas margens do rio, no interior e borda do remanescente florestal com aproximadamente dois hectares. Os indivíduos férteis coletados foram devidamente herborizados, segundo as técnicas usuais (FIDALGO; BONONI, 1984) e identificados, utilizando-se bibliografias especializadas, comparações com exsicatas e auxílio de especialistas. O material coletado foi depositado no Herbário Padre Dr. Raulino Reitz (CRI) da Universidade do Extremo Sul Catarinense (UNESC). As espécies foram reunidas em famílias segundo o sistema de classificação APG III (2009) para as angiospermas e Smith et al. (2006) para as monilófitas (samambaias).

Registraram-se as espécies de acordo com seu hábito arbóreo, arbustivo, herbáceo terrícola, lianescente e epifítico, segundo critérios de Ziparro et al. (2005).

Para as estratégias de polinização e de dispersão e categorias sucessionais consultaram-se bibliografia especializada que descreviam as espécies, como a Flora Ilustrada Catarinense (REITZ, 1964-1989; REIS, 1996-2011) e observações no local, que permitiram, com base em Faegri e van der Pijl (1979) e van der Pijl (1972) reuni-las nas estratégias características destes processos biológicos de polinização e dispersão, respectivamente, e nas categorias sucessionais (FERRETI et al., 1995) adaptado para as formas não arbóreas, sendo a classificação destas realizada para o local de estudo, com base principalmente na observação do ambiente em que se desenvolviam (beira e interior da mata).

\section{RESULTADOS}

Foram encontradas 100 espécies distribuídas em 82 gêneros e 49 famílias, sendo 49 espécies arbóreas, 22 herbáceas terrícolas, 19 arbustivas, seis lianescentes e quatro epífitas (Tabelas 1 e 2).

Tabela 1: Espécies encontradas em remanescente ciliar florestal nas margens do rio Turvo, município de Turvo, Santa Catarina, onde: $\mathrm{H}=$ hábito, sendo: $\mathrm{A}=$ arbóreo, $\mathrm{Ar}=$ arbustivo, $\mathrm{Ht}=$ herbácea terrícola, $\mathrm{Ep}=$ epífito, $\mathrm{Li}=$ lianescente; $\mathrm{GE}=$ grupo ecológico, sendo: Pio = pioneira, Sin = secundária inicial, Sta = secundária tardia, Cli = clímax; Poli = polinização, onde Zoof = zoofílica; Anef = anemofílica; Disp = dispersão, onde: 
Zooc $=$ zoocórica $;$ Anec $=$ anemocórica $;$ Auto $=$ autocórica, Espo $=$ esporocórica $;$ CRI acrônomo do Herbário Pe. Dr. Raulino Reitz, nc = não coletada.

\begin{tabular}{|c|c|c|c|c|c|c|}
\hline Família/Espécie & Nome popular & $\mathrm{H}$ & $\mathrm{GE}$ & Poli & Disp & CRI \\
\hline $\begin{array}{l}\text { Anacardiaceae } \\
\text { Schinus terebinthifolius Raddi } \\
\text { Annonaceae }\end{array}$ & Aroeira-vermelha & A & Pio & Zoof & Zooc & 7896 \\
\hline Guatteria australis A.St.-Hil & Cortiça & A & Sta & Zoof & Zooc & 7690 \\
\hline $\begin{array}{l}\text { Rollinia sericea } \text { R.E.Fr. } \\
\text { Aquifoliaceae }\end{array}$ & Cortiça & A & Sta & Zoof & Zooc & 7881 \\
\hline $\begin{array}{l}\text { Ilex paraguariensis A.St.-Hil } \\
\text { Arecaceae }\end{array}$ & Erva-mate & A & Pio & Zoof & Zooc & 7895 \\
\hline Geonoma gamiova Barb.Rodr. & Palheira & Ar & Sta & Zoof & Zooc & 7888 \\
\hline $\begin{array}{l}\text { Syagrus romanzzoffianum (Cham.) } \\
\text { Glassman } \\
\text { Apocynaceae }\end{array}$ & Jerivá & A & Sta & Zoof & Zooc & 7890 \\
\hline $\begin{array}{l}\text { Asclepias curassavica } \mathrm{L} \text {. } \\
\text { Asteraceae }\end{array}$ & Oficial-de-sala & $\mathrm{Ht}$ & Pio & Zoof & Zooc & 7669 \\
\hline Bidens pilosa $\mathrm{L}$. & Picão & $\mathrm{Ht}$ & Pio & Zoof & Anec & 7676 \\
\hline Chaptalia nutans L. & Lingua-de-vaca & $\mathrm{Ht}$ & Pio & Zoof & Anec & 7639 \\
\hline $\begin{array}{l}\text { Vernonia scorpioides (Lam.) Pers. } \\
\text { Balsaminaceae }\end{array}$ & Assapei & $\mathrm{Ht}$ & Pio & Zoof & Zooc & 7905 \\
\hline $\begin{array}{l}\text { Impatiens waleriana Hook. F.* } \\
\text { Bignoniaceae }\end{array}$ & Maria-sem-vergonha & $\mathrm{Ht}$ & Pio & Zoof & Zooc & 7903 \\
\hline $\begin{array}{l}\text { nda puberula Cham. } \\
\text { eae }\end{array}$ & Caroba & A & Pio & Zoof & Zooc & 7884 \\
\hline $\begin{array}{l}\text { Blechnum brasiliensis Desv. } \\
\text { Bromeliaceae }\end{array}$ & Samambaia & $\mathrm{Ht}$ & Sin & ---- & Espo & 7652 \\
\hline innocentii Lemaire & Gravatá & Ep & Pio & Zoof & Zooc & 7875 \\
\hline eminiflora Brongn. & Cravo-do-mato & Ep & Pio & Zoof & Anec & 7874 \\
\hline $\begin{array}{l}\text { gantea Gaud. } \\
\text { ceae }\end{array}$ & Gravatá & Ep & Pio & Zoof & Anec & 7883 \\
\hline $\begin{array}{l}\text { Trema micrantha }(\text { L.) Blume } \\
\text { Cannaceae }\end{array}$ & Grandiúva & A & Pio & Zoof & Zooc & 7662 \\
\hline $\begin{array}{l}\text { Canna denudata Rosc. } \\
\text { Cactaceae }\end{array}$ & Caité & $\mathrm{Ht}$ & Pio & Zoof & Auto & 7880 \\
\hline $\begin{array}{l}\text { Rhipsalis baccifera (J.S.Muell.) Stearn } \\
\text { Dryopteridaceae }\end{array}$ & Rabo-de-gato & Ep & Pio & Zoof & Zooc & 7879 \\
\hline $\begin{array}{l}\text { Rumohra adiantiformis (G.Forst.) Ching } \\
\text { Euphorbiaceae }\end{array}$ & Samambaia-preta & $\mathrm{Ht}$ & Sin & ---- & Espo & 7653 \\
\hline Alchornea glandulosa Endl. \& Poepp. & $\begin{array}{l}\text { Tanheiro-da-folha- } \\
\text { redonda }\end{array}$ & A & Sin & Zoof & Zooc & 7678 \\
\hline $\begin{array}{l}\text { Alchornea triplinervia (Spreng.) } \\
\text { Mull.Arg. }\end{array}$ & Tanheiro & A & Sin & Zoof & Zooc & 7906 \\
\hline Gymnanthes concolor Spreng. & Limoeiro-d & A & Sta & Anef & Auto & 7680 \\
\hline Sebastiania argutidens Pax et K.Hoffm. & Taju & A & Pio & Anef & Auto & 7654 \\
\hline $\begin{array}{l}\text { Tetrorchidium rubrivenium Poepp. et } \\
\text { Endl. }\end{array}$ & Embirão & A & Sin & Anef & Zooc & 7681 \\
\hline
\end{tabular}




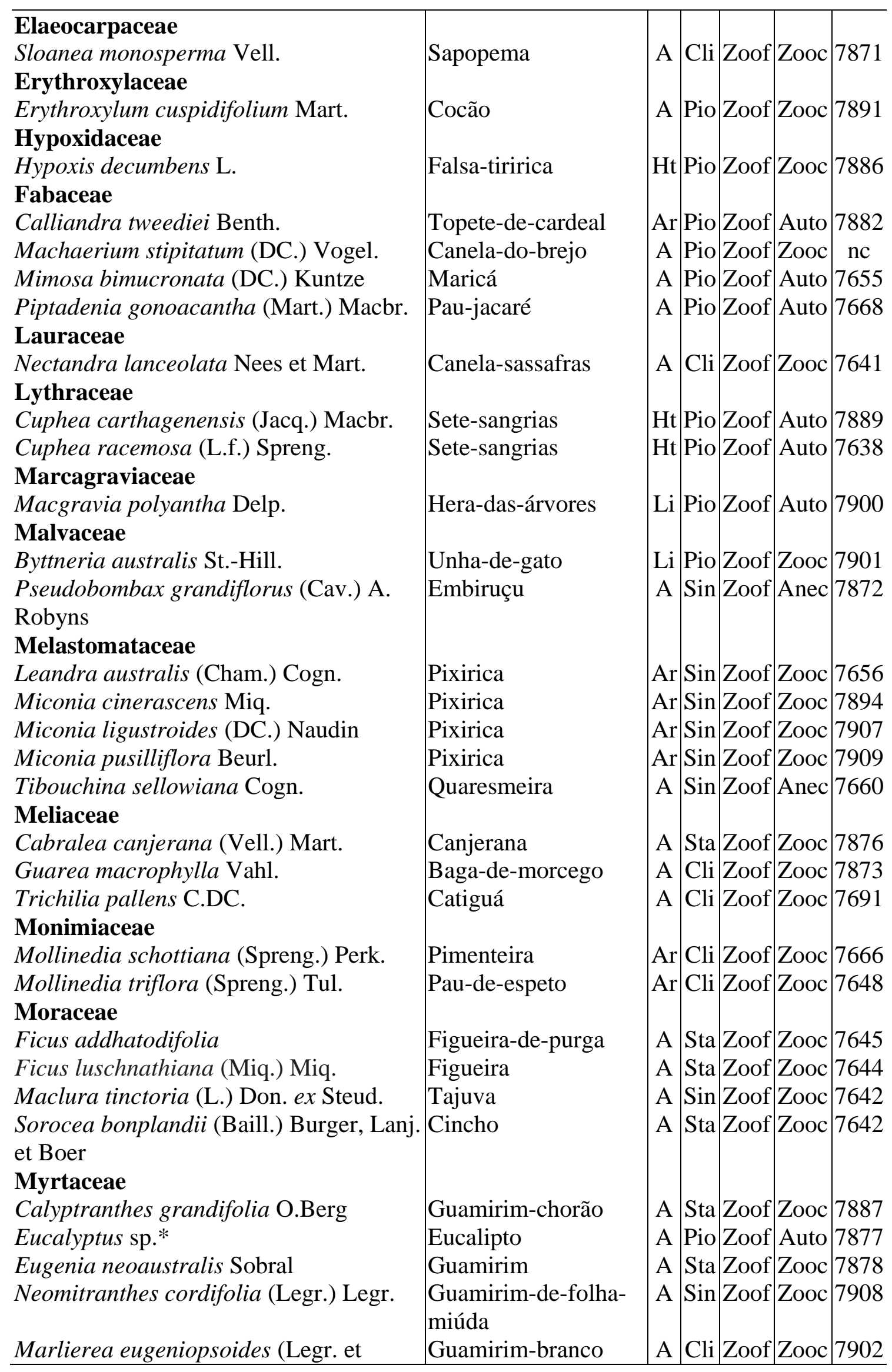




\begin{tabular}{|c|c|c|c|c|c|c|}
\hline$\overline{\text { Kausel) }}$ & & & & & & \\
\hline $\begin{array}{l}\text { Myrcia pubipetala Miq. } \\
\text { Myrcia splendens (Sw.) DC. }\end{array}$ & $\begin{array}{l}\text { Guamirim-araçá } \\
\text { Guamirim-de-folha- } \\
\text { fina }\end{array}$ & $\begin{array}{l}\mathrm{A} \\
\mathrm{A}\end{array}$ & $\begin{array}{l}\text { Sta } \\
\text { Sin }\end{array}$ & $\mid \begin{array}{l}\text { Zoof } \\
\text { Zoof }\end{array}$ & Zooc & 7673 \\
\hline Primulaceae & & & & & & \\
\hline $\begin{array}{l}\text { Myrsine umbellata Mart. } \\
\text { Nyctaginaceae }\end{array}$ & Capororoca & A & Sin & Anef & Zooc & 7904 \\
\hline $\begin{array}{l}\text { Guapira opposita (Vell.) Reitz } \\
\text { Ochnaceae }\end{array}$ & Mari & A & Sin & Zoof & Zooc & 7689 \\
\hline $\begin{array}{l}\text { Ouratea parviflora (DC.) Baill. } \\
\text { Oleaceae }\end{array}$ & Pimenteira-do-mato & $\mathrm{Ar}$ & Sin & Zoof & Zooc & 7679 \\
\hline $\begin{array}{l}\text { Chionanthus filiformis (Vell.) Green } \\
\text { Onagraceae }\end{array}$ & Azei & A & Sta & Zoof & Zooc & 7646 \\
\hline $\begin{array}{l}\text { ia longifolia }(\mathrm{DC} .) \text { H.Hara } \\
\text { laceae }\end{array}$ & Cafe & $\mathrm{Ht}$ & $\operatorname{Sin}$ & Zoof & Zooc & 7683 \\
\hline $\begin{array}{l}\text { achya estrellensis Rchb.F. } \\
\text { oraceae }\end{array}$ & Orq & $\mathrm{Ht}$ & Pio & Zoof & Zooc & 7637 \\
\hline $\begin{array}{l}\text { ora alata Dryander } \\
\text { ceae }\end{array}$ & Ma1 & $\mathrm{Li}$ & Pio & Zoof & Zooc & 7899 \\
\hline duncum L. & Par & $\mathrm{Ar}$ & $\operatorname{Sin}$ & Zoof & Zooc & 7870 \\
\hline Piper gaudichaudianum Kuntze & Par & $\mathrm{Ar}$ & $\operatorname{Sin}$ & Zoof & Zooc & 7640 \\
\hline olmisic & Pari & Ar & $\operatorname{Sin}$ & Zoof & Zooc & 7898 \\
\hline $\begin{array}{l}\text { Piper xylosteoides } \\
\text { Poaceae }\end{array}$ & Pari & $\mathrm{Ar}$ & Sin & Zoof & Zooc & 7897 \\
\hline acrima-iohi y $^{\prime}$ & Lág & $\mathrm{Ht}$ & Pio & Anef & Auto & 7682 \\
\hline Ichnanthus pa & ato & $\mathrm{Ht}$ & $\operatorname{Sin}$ & Anef & Zooc & 7687 \\
\hline Olyra humilis & $\mathrm{Ta}$ & $\mathrm{Ht}$ & Sin & Anef & Auto & 7685 \\
\hline $\begin{array}{l}\text { Olyra latifolia L. } \\
\text { Pteridaceae }\end{array}$ & $\mathrm{Ta}$ & $\mathrm{Ht}$ & $\operatorname{Sin}$ & Anef & Auto & 7664 \\
\hline $\begin{array}{l}\text { Adiantum cuneatum Langsd. et Fisch. } \\
\text { Rubiaceae }\end{array}$ & Ave & $\mathrm{Ht}$ & $\mathrm{Cli}$ & --- & Espo & 7684 \\
\hline $\begin{array}{l}\text { Faramea montevidensis (Cham. et } \\
\text { Schltdl.) DC. }\end{array}$ & Pin & A & $\mathrm{Cli}$ & Zoof & Zooc & 7657 \\
\hline Psychotria brachyce & $\mathrm{Ca}$ & $\mathrm{Ar}$ & $\mathrm{Cli}$ & Zoof & Zooc & 7643 \\
\hline $\begin{array}{l}\text { Psychotria brachypoda (Müll.Arg.) } \\
\text { Britton }\end{array}$ & Pin & $\mathrm{Ar}$ & $\mathrm{Cli}$ & Zoof & Zooc & 7674 \\
\hline Psychotria lei & $\mathrm{Gr}$ & $\mathrm{Ar}$ & Sta & Zoof & Zooc & 7670 \\
\hline Psychotria suterella Müll.Arg. & Café-do-mato & $\mathrm{Ar}$ & $\mathrm{Cli}$ & Zoof & Zooc & 7659 \\
\hline $\begin{array}{l}\text { Galium hypocarpium (L.) Endl. ex } \\
\text { Griseb. }\end{array}$ & -------- & $\mathrm{Li}$ & $\operatorname{Sin}$ & Zoof & Zooc & 7651 \\
\hline $\begin{array}{l}\text { Rudgea jasminoides (Cham.) Müll.Arg. } \\
\text { Rutaceae }\end{array}$ & $\mathrm{Ca}$ & A & $\mathrm{Cli}$ & Zoof & Zooc & 7658 \\
\hline Esenbeckia grandiflora Mart. & $\mathrm{Cu}$ & A & $\operatorname{Sin}$ & Zoof & Auto & 7650 \\
\hline $\begin{array}{l}\text { Zanthoxylum astrigerum (R.S.Cowan) } \\
\text { P.G.Waterman }\end{array}$ & Ma & A & Pio & Zoof & Auto & 7647 \\
\hline $\begin{array}{l}\text { Zanthoxylum rhoifolium Lam. } \\
\text { Rosaceae }\end{array}$ & Mamica-de-cadela & A & Pio & Zoof & Auto & 7663 \\
\hline
\end{tabular}




\begin{tabular}{|c|c|c|c|c|c|c|}
\hline $\begin{array}{l}\text { Rubus erythrocladus Mart. } \\
\text { Salicaceae }\end{array}$ & Amora & & Sin & Zoof & Zooc & 7649 \\
\hline Casearia decandra Jacq. & Guaçatonga & A & Pio & Zoof & Zooc & 7893 \\
\hline Casearia sylvestris $\mathrm{Sw}$. & Chá-de-bugre & A & Sin & Zoof & Zooc & 7675 \\
\hline Sapindaceae & & & & & & \\
\hline Matayba juglandifolia Radlk. & Camboatá & A & Sin & Zoof & Zooc & 7677 \\
\hline $\begin{array}{l}\text { Paullinia trigonia Vell. } \\
\text { Sapotaceae }\end{array}$ & Cipó-timbó & $\mathrm{Li}$ & Sta & Zoof & Zooc & 7693 \\
\hline $\begin{array}{l}\text { Chrysophyllum inornatum Mart. } \\
\text { Solanaceae }\end{array}$ & Aguaí & A & Pio & Zoof & Zooc & 7665 \\
\hline Solanum americanum Mart. & Maria-pretinha & $\mathrm{Ht}$ & Pio & Zoof & Zooc & 7694 \\
\hline Solanum pseudoquina A.St.-Hil & Canema & A & Pio & Zoof & Zooc & 7667 \\
\hline $\begin{array}{l}\text { Solanum variabile Mart. } \\
\text { Schyzaeaceae }\end{array}$ & Jurubeba-velame & Ar & Pio & Zoof & Zooc & 7686 \\
\hline Anemia phyllitidis (L.) Sw. & Samambaia & $\mathrm{Ht}$ & $\operatorname{Sin}$ & --- & Espo & 7868 \\
\hline $\begin{array}{l}\text { Lygodium volubile } \mathrm{Sw} . \\
\text { Urticaceae }\end{array}$ & Ligódio-volúvel & $\mathrm{Li}$ & Pio & ---- & Espo & 7688 \\
\hline Boehmeria caudata Sw. & Urtiga-mansa & Ar & Pio & Zoof & Zooc & 7692 \\
\hline $\begin{array}{l}\text { Cecropia glaziovii Snethl. } \\
\text { Verbenaceae }\end{array}$ & Embaúba & A & Pio & Zoof & Zooc & 7885 \\
\hline $\begin{array}{l}\text { Citharexylum myrianthum Cham. } \\
\text { Zingiberaceae }\end{array}$ & Tucaneira & A & Sin & Zoof & Zooc & 7892 \\
\hline Hedychium coronarium J.Konig* & Lírio-do-brejo & $\mathrm{Ht}$ & Pio & Zoof & Zooc & 7869 \\
\hline
\end{tabular}

*espécie exótica.

As famílias mais representativas quanto ao número de espécies foram Myrtaceae (sete), Rubiaceae (sete), Melastomataceae (cinco), Euphorbiaceae (cinco) Fabaceae (quatro), Moraceae (quatro), Poaceae (quatro) e Piperaceae (quatro), que contribuíram com $40 \%$ do total das espécies levantadas. Dentre as demais famílias, 27 foram registradas representadas por apenas uma espécie. Myrtaceae, Rubiaceae, Fabaceae e Poaceae também foram representativas em levantamentos realizados por Souza e Monteiro (2005) em florestas ripárias no alto rio Paraná, enquanto Fabaceae, Euphorbiaceae eMyrtaceae apresentaram maior riqueza específica em um trecho de mata ciliar na Depressão Central do Rio Grande do Sul (BRACKMANN; FREITAS, 2013).

A maioria das famílias registradas $(44,1 \%)$ na área estava apenas representada por espécies arbóreas. Destas, Myrtaceae, Euphorbiaceae e Moraceae foram identificadas como de maior riqueza específica. Para matas ciliares da região sul catarinense, os levantamentos fitossociológicos realizados por Citadini-Zanette (1995) e Rebello (2006) registraram 47 e 43 famílias, respectivamente, sendo Myrtaceae a que 
apresentou maior riqueza específica, resultado este também encontrado por De Marchi e Jarenkow (2008) para uma mata ribeirinha no rio Camaquã, no Rio Grande do Sul e por Rodrigues e Nave (2001) para as matas ciliares do Brasil extra-amazônico.

Tabela 2: Formas de vida (Hábito) encontradas em remanescente florestal ciliar do rio Turvo, município de Turvo, Santa Catarina, com indicação do número e porcentagem de famílias, gêneros e espécies.

\begin{tabular}{l|c|c|c}
\hline \multirow{2}{*}{ Hábito } & \multicolumn{3}{|c}{ Número de } \\
\cline { 2 - 4 } & Famílias (\%) & Gêneros (\%) & Espécies (\%) \\
\hline Arbóreo & $26(44)$ & $44(52)$ & $49(49)$ \\
Arbustivo & $9(15)$ & $10(12)$ & $19(19)$ \\
Herbáceo terrícola & $16(27)$ & $20(24)$ & $22(22)$ \\
Lianescente & $6(10)$ & $6(7)$ & $6(6)$ \\
Epifítico & $2(4)$ & $4(5)$ & $4(4)$ \\
\hline
\end{tabular}

Os gêneros com maior riqueza específica foram Piper (quatro), Psychotria quatro), Miconia (três) e Solanum (três), reunindo juntos 14\% das espécies. Entre todos, 69 gêneros foram representados por apenas uma espécie.

Seguindo o padrão observado para famílias, a maioria dos gêneros registrados para a área de estudo englobavam apenas espécies arbóreas (Tabela 2). Dentre os mais representativos para essa categoria, citam-se Alchornea, Casearia, Ficus, Myrcia e Zanthoxylum, com duas espécies cada. Com exceção de Ficus, todos os demais gêneros foram citados por Rodrigues e Nave (2001) como os mais frequentes dentre os componentes arbóreo-arbustivos em florestas ciliares do Brasil extra-amazônico.

Dentre as espécies arbóreas registradas na área estudada, destacam-se Alchornea glandulosa, Casearia sylvestris, Guarea macrophylla, Gymnanthes concolor, Matayba juglandifolia e Sorocea bonplandii. Destas, C. sylvestris, G. concolor e S. bonplandiii foram também encontradas na mata ribeirinha do rio Camaquã (DE MARCHI; JARENKOW, 2008) e nas margens do rio Três Cachoeiras no sul de Santa Catarina (REBELLO, 2006). Barbosa (1993) cita A. glandulosa, encontrada na área deste estudo, como de ampla distribuição em florestas ripárias do Estado de São Paulo. Adicionalmente, reunindo as categorias arbóreas e arbustivas, que perfazem 68,00\% do total das espécies encontradas neste estudo, 34 espécies foram registradas no levantamento florístico realizado nas nascentes e nos trechos de rios da bacia hidrográfica do rio Itajaí por Ghoddozi e Frank (2007), evidenciando a 
representatividade florística desse remanescente como área prioritária para conservação da biodiversidade regional.

São poucos os registros sobre as herbáceas terrícolas em matas ciliares, destacando-se o levantamento realizado por Souza e Monteiro (2005), onde são citadas 20 espécies desta categoria, mas somente Solanum americanum é comum a este estudo. Estes autores também mencionam 27 espécies de lianas, sendo Lygodium volubile o único registro comum para a mata ciliar do trecho do rio Turvo.

As epífitas foram pouco representadas (três espécies de Bromeliaceae e uma de Cactaceae), provavelmente porque não foram amostradas de forma tão intensa quanto a vegetação do solo.

Dentre as espécies levantadas no rio Turvo, quatro são exóticas Coix lacrimajobi, Eucalyptus sp., Hedichyum coronarium e Impatiens waleriana. Esta última, conhecida como maria-sem-vergonha, é abundante em locais úmidos e sombreados. $H$. coronarium, conhecido como lírio-do-brejo, constitui-se em agressiva invasora, por se reproduzir vegetativamente por meio de rizomas, ocupando expressivamente vários trechos da grande maioria dos rios da região.

A polinização por animais foi expressivamente maior do que as demais formas de polinização, presente em 96\% das 95 espécies de angiospermas encontradas (Tabela 1). Na categoria das árvores somente $4 \%$ das espécies foram polinizadas pelo vento, enquanto todas as demais espécies arbóreas e todas as outras categorias tiveram polinização zoofílica. Esse resultado ratifica o encontrado por Zoucas (2002) para o sul de Santa Catarina, para as várias formas de vida das plantas da região.

A grande maioria das espécies registradas na área de estudo (73\%) é caracterizada por dispersão zoocórica. Este padrão é similar ao observado, especialmente para espécies arbóreas, em outras localidades de Floresta Atlântica no sul de Santa Catarina, em trechos ciliares (CITADINI-ZANETTE, 1995; ZOUCAS, 2002; ZOUCAS et al., 2004). Esses valores evidenciam a importância da fauna para estas espécies vegetais, assim como o alto número de interações interespecíficas (conectância) que ocorrem nestas formações.

$\mathrm{Na}$ categoria das herbáceas terrícolas, das 22 espécies levantadas, 10 são zoocóricas, seis autocóricas, duas anemocóricas e quatro monilófitas são esporocóricas (Tabela 1). 
Das epífitas registradas, duas possuem dispersão zoocórica e duas são anemocóricas. Madison (1977 apud ZIPARRO et al., 2005) relata que a anemocoria é vantajosa para plantas que habitam o dossel e assim a dispersão pelo vento entre as epífitas é mais frequente do que nas plantas terrícolas de florestas tropicais.

Entre as espécies lianescentes de angiospermas encontradas, quatro são zoocóricas e uma autocórica. A predominância da zoocoria em lianas também foi registrada por Ziparro et al. (2005) para floresta Atlântica no estado de São Paulo.

É interessante salientar que sete gêneros registrados na área de estudo (Alchornea, Cecropia, Eugenia, Ficus, Nectandra, Paullinia, Sloanea e Trema) são citados na literatura como parte da dieta natural de peixes (GOTTSBERGER, 1978; SOUZA-STEVAUX et al., 1994; SOUZA; MONTEIRO, 2005), enfatizando a importância ecológica dessas espécies para o ambiente ciliar.

Considerando os grupos ecológicos da área de estudo, $72 \%$ das espécies pertencem aos estádios iniciais de sucessão (pioneiras e secundárias iniciais) (Tabela 1), resultado da metodologia de coleta que privilegiou também as bordas da floresta.

Em termos de ocupação horizontal, observou-se um gradiente perpendicular a partir da borda do rio Turvo passando pelo interior até a margem externa do fragmento estudado. Como espécies características da porção do terreno mais próxima ao corpo de água registraram-se Alchornea triplinervia, Calliandra tweediei, Casearia sylvestris, Ficus adhatodifolia, Mimosa bimucronata e Pseudobombax grandiflorus. O interior do remanescente estava caracterizado pela presença de Matayba juglandifolia, Nectandra lanceolata, Piptadenia gonoacantha, Psychotria brachyceras, P. brachypoda e Sorocea bonplandii. Na borda externa do fragmento registrou-se Cecropia glaziovii, Lygodium volubile, Macgravia polyantha, Myrsine umbellata, Passiflora alata, Schinus terebinthifolius, Solanum variabile e Trema micrantha. Entende-se que este padrão de distribuição pode subsidiar ações de restauração/recuperação de ambientes ciliares alterados e degradados, como proposto por Oliveira et al. (2005).

\section{CONSIDERAÇÕES FINAIS}

A inclusão de diferentes hábitos, no presente estudo, com informações ecológicas de cada espécie, permitiu uma ampliação no conhecimento florístico das formações ciliares remanescentes na região, necessária para orientar planos de 
conservação da biodiversidade e escolha de espécies para restauração florestal de trechos desprovidos de vegetação, como em Áreas de Preservação Permanente (APP).

Pela riqueza florística encontrada (100 espécies em 49 famílias), o remanescente estudado, embora com visíveis alterações originadas do passado, ainda abriga informações que podem servir de guia para a restauração de áreas ciliares, em condições semelhantes, na bacia do rio Araranguá.

\section{AGRADECIMENTOS}

Os autores agradecem à Universidade do Extremo Sul Catarinense (UNESC) pela bolsa de Iniciação Científica (PIBIC) concedida a dois autores e aos revisores designados, pelas sugestões apresentadas.

\section{REFERÊNCIAS}

ALEXANDRE, N. Z. Análise integrada da qualidade das águas da bacia do Rio Araranguá (SC). 2000. 288 f. Dissertação (Mestrado em Geografia)- Universidade Federal de Santa Catarina, Florianópolis, 2000.

ALVARENGA, A. P. Avaliação inicial da recuperação de matas ciliares em nascentes. 2004. 175 f. Dissertação (Mestrado em Engenharia Florestal)- Universidade Federal de Lavras, Lavras, 2004.

APG III. The Angiosperm Phylogeny Group. An update of the Angiosperm Phylogeny Group classification for the ordens and families of flowering plants: APG II. Botanical Journal of the Linnean Society, London, v. 161, p. 105-121, 2009.

BARBOSA, L. M. Vegetação ciliar: conceitos e informações práticas para conhecer e recuperar trechos degradados. Caderno de Pesquisa, Ser. Bot., Santa Cruz do Sul, v. 5, n. 1, p. 3-36, 1993.

BOTREL, R. T.; OLIVEIRA FILHO, A. T.; RODRIGUES, L. A.; CURI, N. Influência do solo e topografia sobre as variações da composição florística e estrutura da comunidade arbóreo-arbustiva de uma Floresta Estacional Semidecidual em Ingaí, MG. Revista Brasileira de Botânica, São Paulo, v. 25, n. 2, p. 195-213, 2002.

BRACKMANN, C. E.; FREITAS, E. M. Florística arbórea e arbustiva de um fragmento de mata ciliar do Arroio Boa Vista, Teutônia, RS, Brasil. Hoehnea, São Paulo, v.40, n.2, p. 365-372, 2013.

CITADINI-ZANETTE, V. Florística, fitossociologia e aspectos da dinâmica de um remanescente de mata atlântica na microbacia do rio Novo, Orleans, SC. 1995. 249 f. Tese (Doutorado em Ecologia e Recursos Naturais)- Universidade Federal de São Carlos, São Carlos, 1995. 
DE MARCHI, T. C.; JARENKOW, J. A. Estrutura do componente arbóreo de mata ribeirinha no rio Camaquã, município de Cristal, Rio Grande do Sul, Brasil. Iheringia, Ser. Bot., Porto Alegre, v. 63, n. 2, p. 241-248, 2008.

EMBRAPA. Empresa Brasileira de Pesquisa Agropecuária. Sistema brasileiro de classificação de solos: SiBCS (Nova Versão). JACOMINE, P. K. T. et al. (Org.). Rio de Janeiro: Embrapa Solos, 2005. p. 1-16.

FAEGRI, K.; van der PIJL, L. The principles of pollination ecology. 3. ed. Oxford: Pergamon Press, 1979.

FAGUNDES, N. A.; GASTAL JUNIOR, C. V. de S. Diagnóstico ambiental e delimitação de áreas de Preservação em um assentamento rural. Acta Scientiarum. Biological Sciences, Maringá, v. 30, n. 1, p. 29-38, 2008.

FERRETTI, A. R.; KAGEYAMA, P. Y.; ÁRBOCZ, G. F.; SANTOS, J. D.; BARROS, M. I.; LORZA, R. F.; OLIVEIRA, C. Classificação das espécies arbóreas em grupos ecológicos para revegetação com nativas no estado de São Paulo. Florestar Estatístico, São Paulo, v. 3, n. 7, p. 73-77, 1995.

FIDALGO, O.; BONONI, V. L. R. (Coord.). Técnicas de coleta, preservação e herborização de material botânico. São Paulo: Instituto de Botânica, 1984.

FILGUEIRAS, T. S.; NOGUEIRA, P. E.; BROCHADO, A. L.; GUALA II, G. F. Caminhamento: um método expedito para levantamentos florísticos qualitativos. Cadernos de Geociências, Rio de Janeiro, v. 12, p. 39-43, 1994.

FRANK. B. o Projeto Piava: origem, concepção e organização. Revista de Estudos Ambientais, Blumenau, v. 9, n. 1, p. 5-22, 2007.

GHODDOSI, S. M.; FRANK, B. Estudo das tipologias de áreas degradadas e da vegetação na bacia hidrográfica do Itajaí como subsídio para proposta de recuperação de florestas ciliares. Revista de Estudos Ambientais, Blumenau, v. 9, n. 1, p. 253-283, 2007.

GOTTSBERGER, G. Seed dispersal by fisch in the inundated region of Humaita, Amazonia. Biotropica, Lawrence, v. 10, n. 3, p. 170-183, 1978.

GRACIOLI, C. R.; ROCHA, J. S. M. da R. Impactos ambientais na microbacia hidrográfica do rio Vacaraí-Mirim em Santa Maria, RS. Ambiência, Guarapuava, v. 4, n. 1, p. 251-263, 2008.

IBGE. Fundação Instituto Brasileiro de Geografia e Estatística. Manual Técnico da Vegetação Brasileira. Rio de Janeiro: IBGE, 1992.

KAGEYAMA, P. Y.; GANDARA, F. B. Recuperação de matas ciliares. In: RODRIGUES, R. R.; LEITÃO-FILHO, H. F. (Ed.). Matas Ciliares: conservação e recuperação. 2. ed. São Paulo: Edusp/FAPESP, 2001. p. 249-269.

LEITE, P. F.; KLEIN, R. M. . Vegetação. In: IBGE. Geografia do Brasil: Região Sul. Rio de Janeiro: IBGE, 1990. p. 113-187.

LIMA, W. de P.; ZAKIA, M. J. B. Hidrologia de matas ciliares. In: RODRIGUES, R. R.; LEITÃO-FILHO, H. (Ed.). Matas ciliares: conservação e recuperação. 2 ed. São Paulo: Edusp/FAPESP, 2001. p. 33-44. 
MARINHO FILHO, J. S.; REIS, M. L. A fauna de mamíferos associada às matas ciliares de galeria. In: BARBOSA, L. M. (Coord.). SIMPÓSIO SOBRE MATA CILIAR. 1989. Campinas. Anais... Campinas, Fundação Cargill, 1989.

OLIVEIRA, M. L. A. A.; BALBUENO, R. A.; SENNA, R. M. Levantamento florístico de fragmentos florestais na bacia hidrográfica do rio Gravataí, Rio Grande do Sul, Brasil. Iheringia, ser. Bot., v. 60, n. 2, p. 269-284, 2005.

OMETTO, J. C. Classificação Climática. In: OMETTO, J. C. Bioclimatologia vegetal. São Paulo: Agronômica/CERES, 1981. p. 389-404.

PETTS, G. E. The role of ecotones in aquatic landscape management. In: NAIMAN, R.; DÉCAMPS, H. (Ed.). The ecology and management of aquatic-terrestrial ecotones. Paris: The Parthenon Publishing Group, 1990.

REBELO, M. A. Florística e fitossociologia de um remanescente florestal ciliar: subsídio para a reabilitação da vegetação ciliar para a microbacia do rio Três Cachoeiras, Laguna, SC. 2006. 143 f. Dissertação (Mestrado em Ciências Ambientais)Universidade do Extremo Sul Catarinense, Criciúma, 2006.

REIS, A. Flora Ilustrada Catarinense. Itajaí: Herbário Barbosa Rodrigues, 19962011.

REITZ, R. Flora Ilustrada Catarinense. Itajaí: Herbário Barbosa Rodrigues, 19641989.

RODRIGUES, R. R.; NAVE, A. G. Heterogeneidade florística das matas ciliares. In: RODRIGUES, R. R.; LEITÃO-FILHO, H. F. (Ed.). Matas Ciliares: conservação e recuperação. 2. ed. São Paulo: Universidade de São Paulo/FAPESP, 2001. p. 45-71.

SABINO, J.; CASTRO, R. M. C. Alimentação, período de atividade e distribuição espacial dos peixes de um riacho da Floresta Atlântica (sudeste do Brasil). Revista Brasileira de Biologia, São Carlos, v. 50, n. 1, p. 23-26, 1990.

SALIS, S. M.; TAMASHIRO, J. Y.; JOLY, C. C. Florística e fitossociologia do estrato arbóreo de um remanescente de mata ciliar do rio Jacaré-Pepira, Brotas, SP. Revista Brasileira de Botânica, São Paulo, v. 17, p. 93-103, 1994.

SMITH, A. R.; PRYER, K. M.; SCHUETTPELZ, E. KORALL, P.; SCHNEIDER, H.; WOLF, P. G. A. A classification for extant ferns. Taxon, v. 55, n. 3, p. 705-731, 2006.

SOUZA, M. C.; MONTEIRO, R. Levantamento florístico em remanescente de floresta ripária no alto rio Paraná: Mata do Araldo, Porto Rico, Paraná, Brasil. Acta Scientiarum Biological Science, Maringá, v. 27, n. 4, p. 405-414, 2005.

SOUZA-STEVAUX, M. C.; NEGRELLE, R. R. B; CITADINI-ZANETTE, V. Seed dispersal by fish Pterodoras granulosus in the Parana River Basin, Brazil. Journal of Tropical Ecology, Cambridge, v. 10, n. 4, p. 621-626, 1994.

van der PIJL, L. Principles of dispersal in higher plants. 2. ed. Berlim: SpringerVerlag, 1972.

ZIPARRO, V. B.; GUILHERME, F. A. G.; ALMEIDA-SCABBIA, R. J.; MORELLATO, L. P. C. Levantamento florístico de floresta Atlântica no sul do estado de São Paulo, Parque Estadual Intervales, Base Saibadela. Biota Neotropica, v. 5, n. 1. p. 147-170, 2005. 
ZOUCAS, B. C. Subsídios para restauração de áreas degradadas: banco de dados e análise das espécies vegetais de ocorrência no sul de Santa Catarina. 2002. 132 f. Dissertação (Mestrado em Biologia Vegetal)- Universidade Federal de Santa Catarina, Florianópolis.

ZOUCAS, B. C.; CITADINI-ZANETTE, V.; SANTOS, R. Relações interespecíficas na recuperação de áreas degradadas. Revista de Tecnologia e Ambiente, Criciúma, v. 10, n. 2, p. 81-97, 2004. 